\title{
Proposta de um serviço de manutenção e pós-venda para empresa de autoclaves
}

Proposal for a maintenance service and after-sales for autoclaves company

MAHFUD, Deborah Cristine; Mestranda em Design; Universidade da Região de JoinvilleUNIVILLE.

dehmahfud@gmail.com

SCHMIDT, Marco Aurélio; Mestre em Design; Universidade da Região de Joinville- UNIVILLE. marcoaurelioschmidt@gmail.com

CAMARGO, Mayra; Mestranda em Design; Universidade da Região de Joinville- UNIVILLE. my.camargo15@hotmail.com

TAVARES, Raphael Alexandre; Mestre em Design; Universidade da Região de JoinvilleUNIVILLE.

raphael.tavares@univille.br

AGUIAR, Victor Rafael Laurenciano; Doutor em Educação; Pontifícia Universidade Católica de São Paulo- PUC-SP.

cdht@uol.com.br

PRUNER, Fernando Pereira; Mestre em Engenharia de Produção; Universidade Federal de Santa Catarina- UFSC.

fernando_pruner@whipool.com

\section{Resumo}

O presente artigo teve como objetivo o desenvolvimento de um serviço para uma empresa de autoclaves da cidade de Joinville/SC, utilizando ferramentas de design. O artigo faz uma contextualização sobre serviços, fabricantes como fornecedores dos mesmos e Design de serviços, apresentando a metodologia da pesquisa, o estudo proposto e os resultados esperados com a implementação da proposta na empresa de autoclaves. Como resultado, a pesquisa traz o serviço desenvolvido e espera-se que com a aplicação dele, o mesmo seja capaz de aumentar a lucratividade e a fidelização dos clientes da empresa.

Palavras Chave: design de serviço; serviços de pós-venda; fidelização de cliente. 


\section{Abstract}

The present article had the objective of developing a service for an autoclave company in the city of Joinville / SC, using design tools. The article makes a contextualization about services, manufacturers as suppliers of them and Services design, presenting the methodology of the research, the proposed study and the expected results with the implementation of the proposal in the company of autoclaves. As a result, the research brings the service developed and it is expected that with the application of it, it will be able to increase profitability and customer loyalty of the company.

Keywords: service design; after-sales services; customer loyalty.

\section{Introdução}

No Brasil, o mercado competitivo e as crises econômicas obrigam empresas a diversificarem seus produtos a fim de aumentar a rentabilidade e agregar valor à sua marca. Empresas de diversos segmentos estão gradativamente investindo no mercado de serviços com o intuito de estreitar o relacionamento com cliente, identificar novos nichos de atuação, aumentar vendas e garantir sustentabilidade ao negócio. Oferecer serviço tem se tornado uma necessidade para sustentar e ampliar os negócios frente ao mercado atual, Lovelock (2001) justifica esta realidade ao afirmar que:

\footnotetext{
As economias modernas são movidas por empresas de serviço, tanto pelas grandes como pelas pequenas. Os serviços são responsáveis pela criação de uma maneira significativa de novos trabalhos, qualificados ou sem qualificação, no mundo inteiro. O setor de serviços envolve uma enorme diversidade de atividades diferentes, entre elas muitas atividades fornecidas por organizações públicas e sem fins lucrativos. $\mathrm{O}$ setor representa mais da metade da economia na maioria dos países em desenvolvimento e mais de $70 \%$ em muitas economias altamente desenvolvidas (LOVELOCK, 2001, p. 27).
}

O estudo de caso realizado neste artigo contempla o mapeamento de processos e identificação de oportunidades, tendo como objetivo o desenvolvimento de um serviço por meio de ferramentas de Design. Este processo foi desenvolvido para uma empresa fabricante de autoclaves industriais que realiza beneficiamento de madeira, esterilização de produtos hospitalares e vulcanização de borrachas, localizada na cidade de Joinville/ SC. Como os objetivos do estudo são melhorar o relacionamento com o cliente, proporcionar a fidelização da marca e gerar aumento efetivo do lucro, verificou-se que o serviço de pós venda é capaz de alcançar esses anseios.

Para tanto, será contextualizado o cenário, oportunidades e tendências do Design de Serviços como ferramentas estratégicas para aumento de faturamento. Atuação em novos nichos de mercado, valor da marca visando à longevidade sustentável da empresa e capacidade de inovação frente ao mercado competitivo serão outros quesitos abordados. Será utilizada uma ferramenta da metodologia de Design de Serviços para o estudo de caso, o Blueprint, além de ferramentas de design para a obtenção de oportunidades visando uma análise mais aprofundada dentro do estudo.

As análises dos resultados demonstrarão os potenciais benefícios para empresa estudada, com a implantação dos serviços propostos no estudo. Serão destacadas as necessidades de adaptação da empresa e os requisitos para pleno atendimento do serviço no mercado conforme o aumento da demanda. 


\section{Serviço}

O termo serviço é algo muito propagado no mercado atual, porém muitas vezes não sabemos defini-lo ou diferenciá-lo, apesar de utilizarmos diversos tipos de serviços todos os dias. Assistir TV, filmes no "NETFLIX", andar de ônibus, falar ao telefone são alguns exemplos de serviços dos quais fazemos uso diariamente. Este é um termo amplo dentro do mercado produtivo, não é algo tangível e muitas vezes é difícil compreender seu funcionamento.

Segundo Kotler (1988, p. 191), "Serviço é qualquer atividade ou benefício que uma parte possa oferecer a outra, que seja essencialmente intangível e não resulte na propriedade de qualquer coisa. Sua produção pode estar ou não vinculada a um produto físico." Serviço nada mais é que suprir as necessidades do cliente, atender seus anseios, buscar soluções, inovar, agregar valor para resolução de uma necessidade. Por ser uma atividade ou um conjunto de atividades, serviços ou bens de serviços apresentam algumas características que ajudam na sua diferenciação.

Oferecer serviços é uma forma inovadora de atender as necessidades do cliente e obter lucro. Empresas de bens de consumo devem enxergar esse modo/atividade de mercado como uma oportunidade para novos negócios podendo assim ampliar sua gama de atividades.

Quando o cliente compra um produto, ele adquire o serviço que espera daquele produto, ou seja, um produto presta um serviço (KOTLER, 2009). A satisfação do cliente está diretamente ligada a sua expectativa, se ele recebe o que espera, fica satisfeito, por outro lado recebendo menos do que espera fica frustrado e insatisfeito. "A meta é a satisfação do cliente, o que se pode traduzir em uma conta simples: o que se espera em função do que efetivamente se recebe" (AGUIAR, 2014, p.19).

O que é bom ou ruim em uma prestação de serviço será definido pela avaliação do cliente, de acordo com a adequação ao uso, destacando a importância das organizações conhecerem as expectativas de seus clientes, pois só assim terão parâmetros para perceberem se a atingiram, podendo ainda superá-las tornando o cliente satisfeito e ainda fã, atingindo o chamado ciclo virtuoso (AGUIAR, 2014).

Figura 1 - Ciclo virtuoso do atendimento

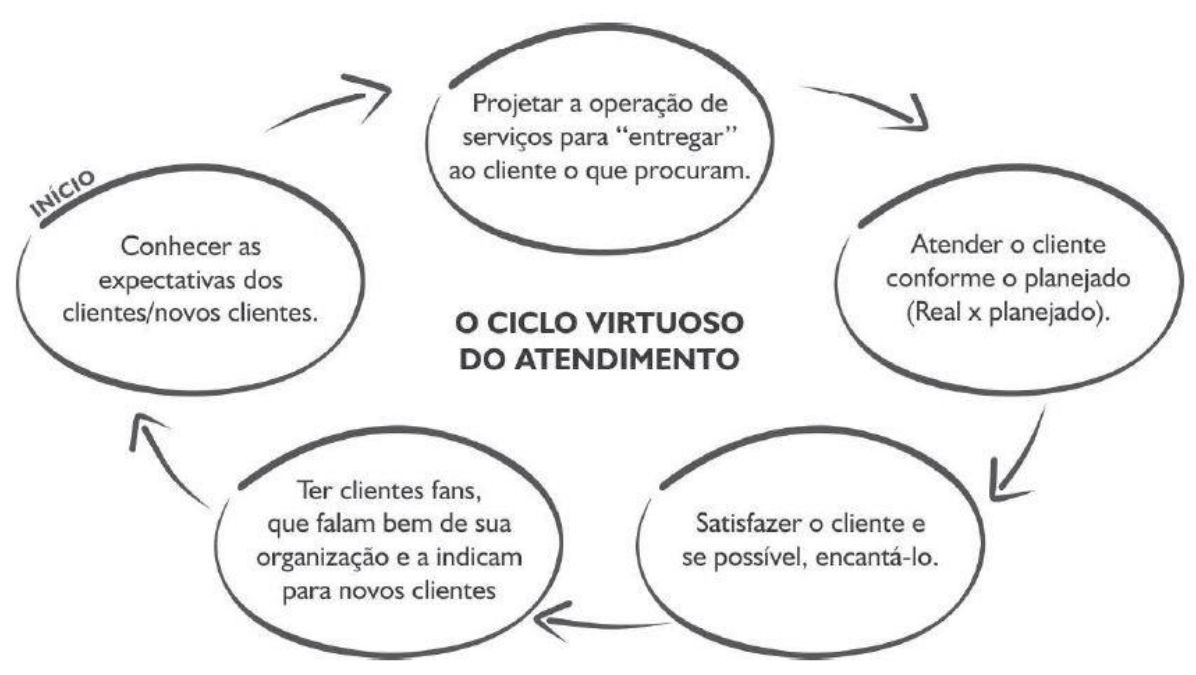

Fonte: Aguiar (2014) 
Portanto, tomando como parâmetro a satisfação do cliente, tratando-se de prestação de serviço, o ciclo virtuoso do cliente (figura 1), torna-se uma máxima a ser utilizada como meta, tendo em vista um produto e serviço de excelência resultando em clientes satisfeitos.

\section{Fabricantes como fornecedores de serviços}

Atualmente fabricantes de produtos encontram grandes oportunidades de mercado na área de serviços. Existe uma extensa gama de atividades que podem ser desempenhadas, tendo em vista que alguns serviços se tornam essenciais para dar suporte às vendas de bens e chegam ao nível de visar seus próprios lucros. Como é o caso da Caterpillar, fabricante que presta serviços junto com seu produto, comprometendo-se a reparar os equipamentos produzidos por ela em qualquer lugar do mundo em até 24 horas e com isso obtém $60 \%$ dos seus lucros vendendo peças e serviços pós-venda (KOTLER, 2009).

À medida em que clientes contratam um serviço de empresa concorrente "Y" pelo fato da empresa " $X$ " não oferecer o mesmo serviço para suprir uma necessidade ou deficiência pelo bem adquirido, demonstra uma oportunidade ou necessidade de um serviço a ser oferecido pelo fabricante "X".

Muitos fabricantes optam por não entrar no ramo de serviços pelo medo de arriscar, e estão muitas vezes apoiados por seus colaboradores como, por exemplo, um gerente antigo na casa, que apresenta receio/sinais de comodismo para atuar em uma área até então desconhecida por ele. Segundo Lovelock (2001), empresas se preocupam em contratar gerentes inovadores que questionam os métodos tradicionais de negócio, trazendo novos métodos de acordo com experiências anteriores.

A ideia de trabalhar com serviços apresenta grandes chances de lucros ao fabricante, apoiado ao fato de que o mercado está crescendo e se tornando cada vez mais competitivo.

\section{Design de serviço}

Neste contexto em que serviços são importantes na economia mundial e empresas observam este fator como diferencial competitivo, oferecer um "bom serviço" se torna essencial na busca pela conquista de clientes.

Com a evolução da tecnologia, empresas prestadoras de serviços começam a observar que para não parar no tempo, devem utilizá-la a seu favor, com isso, o número de serviços cresceu ainda mais fundamentado no design.

O design de serviço é, segundo a Livework (2016) "uma aplicação do design que coloca pessoas em primeiro lugar para projetar experiências de serviços em vez de produtos ou peças gráficas". Portanto, o design de serviço prioriza as pessoas antes de pensar nas organizações ou empresas, o cliente é substancial no projeto, já que o serviço será oferecido a ele e tem por objetivo superar suas expectativas. O projeto Draft explica como funciona a lógica do design de serviço e para que ele serve:

Para planejar e organizar pessoas, infraestruturas, comunicação e serviços para melhorar tanto a qualidade quanto a interação entre contratantes e consumidores. $\mathrm{O}$ Design de Serviço procura entender o problema como um todo, analisar todos os atores em cena e mexer em todas as variáveis possíveis [...] (DRAFT, 2016).

Para projetar serviços é preciso conhecer bem os consumidores e estabelecer vínculos com os mesmos, além de entender sobre o negócio, pessoas e performances. A Livework, 
estúdio de design de serviço, destaca a importância da participação do consumidor durante o planejamento de um serviço, "por melhor que seja o desenho do processo, toda interação com o consumidor é um ato de coprodução" (LIVEWORK, 2016). Assim, mesmo com o projeto desenvolvido, o consumidor tem a oportunidade de experimentá-lo e dar suas opiniões.

Com isso compreende-se que o foco principal do design de serviço está na interação entre todas as partes envolvidas no processo, trazendo um olhar direcionado às pessoas, infraestruturas, comunicação e serviços, além das experiências do consumidor relacionadas ao processo desenvolvido.

\section{Metodologia}

Esta pesquisa possui caráter qualitativo tendo como objetivo principal a criação de um serviço para uma empresa de autoclaves da região de Joinville/SC. Para tanto, fomos a campo em uma visita ao fabricante, onde foi realizado um relato das atividades da empresa, campo de atuação no mercado, posicionamento, valores tendo sido aberto aos convidados a oportunidade de desenvolver serviços que auxiliassem o desenvolvimento da empresa em estudo.

Para identificar as necessidades e oportunidades do agora nosso cliente, foram utilizadas algumas ferramentas de design como: Brainstorming, mapa mental, fluxograma e Blueprint.

O Brainstorming foi utilizado na fase de surgimento das ideias, para que o maior número de caminhos possíveis fosse considerado. De acordo com Baxter (2000):

\footnotetext{
Uma sessão clássica de brainstorming envolve um grupo com cerca de 10 pessoas sentadas em torno de uma mesa, apresentando ideias sobre um problema, tendo como principal característica que pessoas vão dando sugestões de forma bastante livre e sem julgamentos, é o momento em que as ideias vão fluindo e inspirando as outras pessoas, sugerindo soluções para os problemas.
}

O Brainstorming não traz soluções imediatas, é como o próprio termo, faz referência a uma "tempestade de ideias" que vislumbra um cenário amplo a ser trabalhado e lapidado. Esse método auxilia o time a visualizar uma grande variedade de soluções de design antes de efetivamente decidirem com qual opção deverão considerar para as próximas etapas (TEIXEIRA, 2014).

Já numa próxima etapa foi desenvolvido um mapa mental, que serviu para colocar as ideias trazidas no Brainstorming em ordem através de palavras-chaves, partindo do conceito central, irradiando-se posteriormente. Segundo Palzimo (2015), como é uma ferramenta versátil, pode ser aplicado na fase de planejamento e também nas fases de síntese e criatividade, na obtenção de ideias.

Para ilustrar as etapas do serviço de pós-venda, foi utilizado um fluxograma. Assim, as cinco fases foram dispostas e interligadas de modo a exemplificar como funcionaria a relação entre empresa e cliente. E por fim, o Blueprint, foi utilizado para sistematizar o serviço de forma mais ampla, para que depois o fluxograma detalhasse melhor cada fase.

Segundo o escritório de Design Livework (2016), a ferramenta Blueprint nasceu em 1984, quando G.LynnShostack, então vice-presidente do Citibank, propôs uma maneira mais organizada e metódica de estruturar e olhar para os serviços. O Blueprint é muito parecido com um fluxograma, mas o seu modelo carrega um conceito fundamental: o foco nas pessoas que utilizarão o serviço. O objetivo é entender como o serviço funciona atualmente e visualizar oportunidades.

A ferramenta Blueprint, "é útil para visualizar o caminho que os consumidores percorrem 6o GAMPI Plural, 2017, Joinville, SC. 
em múltiplos canais (site, serviço de atendimento ao consumidor, loja física etc.) e para identificar oportunidades de melhoria" (TEIXEIRA, 2016, web). Ao utilizar a ferramenta podese visualizar cenários de serviços e jornada dos clientes, as quais indicarão como diferentes públicos utilizarão o serviço, possibilitando a definição dos requisitos básicos para se entregar uma experiência. O primeiro momento consiste em perceber as ações realizadas pelo usuário, desde a descoberta do serviço a entrega final. Um Blueprint é linear e mostra as ações mais comuns realizadas pelos clientes ao interagir com uma organização.

Após a primeira etapa, identificam-se os principais canais que o cliente se relaciona com o serviço e, no cruzamento entre ações e canais, os pontos de contato, que é onde a relação acontece. Esses canais podem ser website, aplicativos, contato pessoal ou por telefone. Pode-se determinar as funcionalidades de cada canal e encontrar problemas na experiência pelo atendimento ao cliente, sendo possível optar por entregar um serviço específico através de um canal e não outro, de maneira mais consciente quanto ao impacto dessa decisão na jornada do cliente.

É importante considerar o que acontece na empresa e que não é visível ao cliente, são ações, processos e sistemas que são fundamentais para que as ações do usuário possam ser realizadas, mas das quais o cliente não participa ou influencia.

Para a visualização da estrutura do serviço e dos pontos de contado com o consumidor da empresa em estudo, foi utilizada a ferramenta do Blueprint considerando a jornada do consumidor, e as ações da empresa em cada fase de operação.

\section{Estudo proposto}

Apoiado ao fato de que os serviços se tornam fundamentais para empresas no mercado atual e observando que empresas de bens buscam cada vez mais trazer opções de serviços para seus clientes para se diferenciar no mercado, a presente pesquisa tem como objetivo a criação de um serviço para uma empresa de autoclaves da região de Joinville/SC, buscando a fidelização de seus clientes.

\subsection{Objetivos do estudo de caso}

Com base no método de design de serviço foram mapeadas as oportunidades compatíveis com a empresa. Para tanto, recorreu-se a pesquisas de serviços oferecidos por outras empresas do mesmo ramo ou de ramos semelhantes e visita "in loco" para conhecer melhor o cliente, onde se teve a oportunidade de obter informações mais detalhadas sobre o mercado de atuação do mesmo.

Utilizando o Brainstorming, com o objetivo de pontuar um número diverso de ideias, as oportunidades encontradas foram:

- $\quad$ Serviço de pós venda + manutenção;

- $\quad$ Projeto de produto e instalação total do equipamento, incluindo bases estruturais, projeto, licenças, etc.;

- $\quad$ Sistema de manutenção preventiva baseado em modelos automotivos;

- $\quad$ Máquinas de aluguel;

- $\quad$ Fidelização do cliente no pós venda com oferta de serviços complementares.

Após pontuar as oportunidades encontradas, partiu-se para a escolha da melhor opção. Nessa etapa, o foco na fidelização e satisfação do cliente foi tomado como objetivo principal. De acordo com Rodrigues et. al. (2011, p. 5), "a fidelização dos clientes de uma empresa está 
ligada a satisfação que os mesmo obtém com o produto e/ou serviço que adquirem, ou seja, se a empresa consegue satisfazer esse cliente na plenitude de suas expectativas, esse cliente tornará fiel a empresa."

Em conversa com o gestor da empresa estudada, o mesmo indicou que a prioridade é a qualidade de seus produtos, então começou a se observar o que mais poderia tornar essa satisfação completa e ao mesmo tempo promover a fidelização dos clientes. O primeiro passo foi observar os serviços que a empresa fornece buscando oportunidades, fazendo um mapeamento do processo realizado pela empresa com foco no cliente.

Através da ferramenta Blueprint, foram identificadas as fases de venda em que ocorre contato entre empresa e cliente. Assim, foram consideradas as fases de primeiro contato, desenvolvimento e pós-venda. Em cada uma das fases, foram identificados os serviços oferecidos ao cliente e as atividades que propiciam o contato dele com a empresa, desde o reconhecimento da mesma (primeiro contato), passando pela fase de venda do produto (desenvolvimento) até chegar ao pós-venda. Constatou-se assim, os seguintes itens, demonstrados na tabela a seguir:

\begin{tabular}{|c|c|c|c|}
\hline & Primeiro contato & Desenvolvimento & Pós-venda \\
\hline Cliente & $\begin{array}{l}\text {-Site } \\
\text {-Telefone } \\
\text {-Chat } \\
\text {-E-mail } \\
\text {-Indicação } \\
\text {-Feiras } \\
\text {-Site de pesquisa } \\
\text {-Parceiros } \\
\text {-Anúncios }\end{array}$ & $\begin{array}{l}\text {-Financiamento } \\
\text {-Fundamento civil } \\
\text {-Licença ambiental } \\
\text {-Contato com transportadoras }\end{array}$ & $\begin{array}{l}\text { - Contato quando necessário } \\
\text { realizar reclamações, problemas ou } \\
\text { dúvidas }\end{array}$ \\
\hline Empresa & $\begin{array}{l}\text {-Orçamento } \\
\text {-Retorno/ contato com o cliente } \\
\text {-Proposta de venda, condições de } \\
\text { pagamento } \\
\text {-Financiamento }\end{array}$ & $\begin{array}{l}\text {-Projeto do produto e projeto -de } \\
\text { base civil } \\
\text {-Testes } \\
\text {-Certificações } \\
\text {-Liberação para entrega } \\
\text {-Instalação e treinamento }\end{array}$ & $\begin{array}{l}\text {-Atendimento ao cliente quando } \\
\text { existe reclamações e problemas } \\
\text { com o produto } \\
\text {-Instruções por telefone } \\
\text {-Garantia de } 1 \text { ano para } \\
\text { componentes eletrônicos e } \\
\text { terceirizados }\end{array}$ \\
\hline
\end{tabular}

Fonte: Primária (2017)

De acordo com os dados obtidos, observou-se que a relação de pós-venda precisa ser estreitada, pois o contato só acontece quando há uma reclamação em relação ao produto adquirido, quando é necessário a solicitação de atendimento. Desta forma, foi identificada como prioridade ampliar os pontos de contato com o cliente criando novas oportunidades. Sendo assim o plano de serviço foi definido, optando pelo serviço de pós venda de manutenção com o objetivo de fidelizar os clientes da empresa, agregar valor à marca e gerar renda através de novos serviços. O contato com o cliente é essencial para que ele fique satisfeito com o serviço e assim a imagem da marca se sobressaia diante das concorrentes e também para conquista de novos clientes.

\subsection{Proposta de serviço e pós-venda}

Estreitar a relação com o cliente e ampliar os pontos de contato é fundamental para a apresentação das vantagens do serviço de pós-venda e é uma estratégia de fidelizar o cliente 


\section{GAMPI
plural ${ }^{17}$}

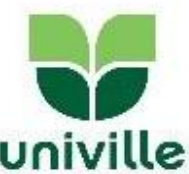

junto a marca da empresa. A proposta do serviço é resultante do estudo elaborado por meio do Blueprint, que é uma ferramenta de design de serviço usado para o mapeamento geral do fluxo do funcionamento do serviço proposto. As etapas do serviço dividiram-se em 5 fases, sendo a fase 1 o contato de pós-venda e venda do serviço de manutenção preventiva, fase 2, 3, 4 e 5 são destinados a execução das atividades do serviço até o encerramento do ciclo. Na imagem 2 , podem ser observadas cada uma das fases do serviço:

Figura 2- Fluxograma do Serviço



Fonte: Primária (2017)

A fase 1 do processo definiu-se como a etapa de pós-venda, que será exemplificada na tabela abaixo:

\begin{tabular}{|c|l|l|}
\hline \multicolumn{2}{|c|}{ FASE 1 } \\
\hline ETAPA & ATIVIDADE & DESCRIÇÃO DA ATIVIDADE \\
\hline 1 & Levantamento dos & Levantamento dos clientes que adquiriram autoclaves; tipos adquiridos; \\
\hline \multicolumn{3}{|c}{ 6o GAMPI Plural, 2017, Joinville, SC. }
\end{tabular}




\begin{tabular}{|c|l|l|}
\hline clientes da empresa: & $\begin{array}{l}\text { datas e números de série das autoclaves; contato para manutenção; } \\
\text { histórico de manutenção; e levantamento de histórico de garantia. }\end{array}$ \\
\hline $\mathbf{2}$ & $\begin{array}{l}\text { Elaboração de lista } \\
\text { de clientes: }\end{array}$ & $\begin{array}{l}\text { Organização de listagem de clientes de acordo com os dados obtidos no } \\
\text { levantamento. }\end{array}$ \\
\hline $\mathbf{3}$ & $\begin{array}{l}\text { Contato com } \\
\text { clientes: }\end{array}$ & $\begin{array}{l}\text { Realização de contato via telefone e/ou e-mail com clientes com histórico } \\
\text { de manutenção; histórico de solicitação de garantia; clientes que } \\
\text { adquiriram autoclaves mais antigas e clientes que recém adquiriram } \\
\text { autoclaves. }\end{array}$ \\
\hline $\mathbf{4}$ & $\begin{array}{l}\text { Ofertar serviço de } \\
\text { manutenção } \\
\text { preventiva: }\end{array}$ & $\begin{array}{l}\text { Ofertar serviço de manutenção preventiva para clientes com histórico de } \\
\text { manutenção, para histórico de solicitação de garantia, para clientes que } \\
\text { adquiriram autoclaves mais antigas e para clientes que recém adquiriram } \\
\text { autoclaves. }\end{array}$ \\
\hline $\mathbf{5}$ & $\begin{array}{l}\text { Comunicar } \\
\text { vantagens desse } \\
\text { serviço }\end{array}$ & $\begin{array}{l}\text { Garantia estendida de cinco anos para novos equipamentos adquiridos; } \\
\text { visitas técnicas periódicas para avaliação e diagnóstico de manutenção } \\
\text { periódicos por hora máquina trabalhada ou mensal; orçamento de peças } \\
\text { de reposição; instalação no local; pacote mensal ou anual. }\end{array}$ \\
\hline
\end{tabular}

Após a venda, a fase 2 do serviço deve ser prestada de forma competente e eficaz, para que o cliente se sinta satisfeito. Para tanto, seguem as etapas:

\begin{tabular}{|c|c|c|}
\hline \multicolumn{3}{|r|}{ FASE 2} \\
\hline ETAPA & ATIVIDADE & DESCRIÇÃO \\
\hline 1 & $\begin{array}{l}\text { Levantamento de dados } \\
\text { para controle do serviço: }\end{array}$ & $\begin{array}{l}\text { Ano da máquina; modelo da máquina; tipo da máquina (madeira, } \\
\text { hospitalar ou borracha); média de horas de máquina; histórico de } \\
\text { manutenção; histórico de solicitação de garantia; e endereço da } \\
\text { máquina. }\end{array}$ \\
\hline 2 & $\begin{array}{l}\text { Monitoramento e } \\
\text { controle do serviço: }\end{array}$ & $\begin{array}{l}\text { Controle das horas trabalhadas da máquina; data da última visita } \\
\text { e/ou manutenção (caso já possui o serviço); e contato com o cliente } \\
\text { para agendar visita de controle (periódico conforme data das horas } \\
\text { máquina trabalhada). }\end{array}$ \\
\hline 3 & $\begin{array}{l}\text { Agendamento de visita } \\
\text { técnica: }\end{array}$ & Local; data; hora; e custo (se houver). \\
\hline 4 & $\begin{array}{l}\text { Comunica técnico para } \\
\text { data agendada: }\end{array}$ & $\begin{array}{l}\text { Comunica local da visita; data da visita; hora da visita; e repassa custo } \\
\text { (se houver). }\end{array}$ \\
\hline
\end{tabular}

Em seguida, na fase 3, acontece a visita do técnico e a prestação do serviço, onde ocorre a checagem total da máquina e seus componentes, de acordo com as etapas: 


\begin{tabular}{|c|l|l|}
\hline \multicolumn{2}{|l}{} \\
\hline ETAPA & ATIVIDADE & DESCRIÇÃO \\
\hline $\mathbf{1}$ & $\begin{array}{l}\text { Check de horas de } \\
\text { uso do produto: }\end{array}$ & $\begin{array}{l}\text { Verifica se a máquina trabalha conforme o previsto no controle e registra } \\
\text { divergências (se necessário). }\end{array}$ \\
\hline $\mathbf{2}$ & Vistoria geral: & $\begin{array}{l}\text { Verifica funcionamento, qualidade das peças, componentes eletrônicos, } \\
\text { performance, segurança, indícios de mal uso e integridade estrutural. }\end{array}$ \\
\hline $\mathbf{3}$ & $\begin{array}{l}\text { Geração de } \\
\text { diagnóstico: }\end{array}$ & $\begin{array}{l}\text { Elabora relatório técnico, preenche checklist de qualidade e anexa na } \\
\text { máquina selo do diagnóstico. }\end{array}$ \\
\hline $\mathbf{4}$ & $\begin{array}{l}\text { Selo do diagnóstico: } \\
\text { Em análise (não conforme), ação de comunicar empresa de autoclave e/ } \\
\text { ou revisado (conforme), nome, data, hora, hora da máquina e data/ ou } \\
\text { hora máquina da próxima revisão. }\end{array}$ \\
\hline & $\begin{array}{l}\text { Contato com a } \\
\text { empresa de autoclave }\end{array}$ & \begin{tabular}{l} 
Informar da necessidade de manutenção. \\
\hline
\end{tabular} \\
\hline
\end{tabular}

Após a empresa ser comunicada, na fase 4 retorna-se à empresa a responsabilidade das tarefas do serviço de pós venda, que se baseiam em:

\begin{tabular}{|c|l|l|}
\hline \multicolumn{2}{|l}{ FASE 4 } \\
\hline ETAPA & ATIVIDADE & DESCRIÇÃ̃o \\
\hline 1 & $\begin{array}{l}\text { Análise do diagnóstico } \\
\text { técnico: }\end{array}$ & $\begin{array}{l}\text { Analisa relatório técnico; analisa checklist de qualidade; e define } \\
\text { as ações. }\end{array}$ \\
\hline 2 & Definição das ações: & $\begin{array}{l}\text { Reposição por garantia; reposição fora da garantia; ou sem } \\
\text { reposição. }\end{array}$ \\
\hline
\end{tabular}

As ações são divididas em três que correspondem à ultima fase do processo, a fase 5 , que se desdobra em:

\begin{tabular}{|c|l|l|}
\hline \multicolumn{2}{|l|}{ FASE 5 } \\
\hline ETAPA & ATIVIDADE & DESCRIÇÃo \\
\hline $\mathbf{1}$ & $\begin{array}{l}\text { Reposição por } \\
\text { garantia: }\end{array}$ & $\begin{array}{l}\text { Empresa faz três cotações das peças, solicitado no relatório técnico; compra as } \\
\text { peças, solicitado no relatório técnico; e agenda nova visita para instalação das } \\
\text { peças. }\end{array}$ \\
\hline $\mathbf{2}$ & $\begin{array}{l}\text { Reposição fora } \\
\text { da garantia: }\end{array}$ & $\begin{array}{l}\text { Empresa faz três cotações das peças, solicitado no relatório técnico dos } \\
\text { fornecedores qualificados e encaminha as três cotaç̃̃es para o cliente comprar } \\
\text { os componentes solicitados dos fornecedores qualificados; cliente compra as } \\
\text { peças do fornecedor que melhor atende sua necessidade; o cliente comunica a } \\
\text { empresa de autoclave para agendar substituição; a empresa recebe confirmação } \\
\text { de compra dos componentes solicitados no relatório técnico e agenda nova }\end{array}$ \\
\hline
\end{tabular}




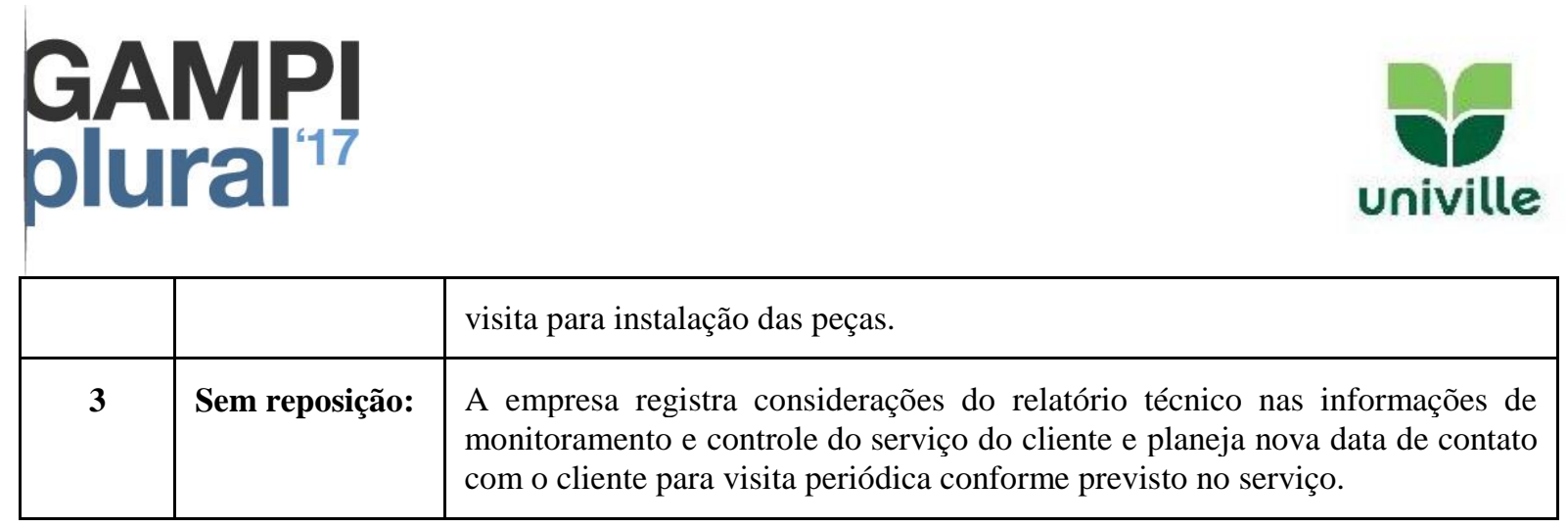

Em caso de manutenção e substituição de peças, a empresa entra em contato com o cliente e agenda uma nova data para o técnico realizar o serviço de substituição e sanar qualquer problema existente ou futuro.

O serviço descrito reinicia o ciclo ao término da etapa da fase 5 , retornando para a fase 2 para clientes que já adquiriram o serviço de manutenção preventiva. Para novas prospecções, a fase 1 é destinada a identificar oportunidades, informacional e identificar potenciais clientes para a venda do serviço, que quando adquirido, segue o fluxo para a fase 2 e assim sucessivamente.

\section{Análise dos resultados}

Através do desenvolvimento do novo serviço de pós- venda, espera-se que ocorra uma maior proximidade da empresa com seus clientes através de um serviço de pós-venda eficiente. Também acredita-se que os novos serviços possam agregar valor à marca, fortalecer a mesma no mercado e gerar novas possibilidades de lucro, através da diversificação dos serviços prestados.

O serviço poderá também impulsionar os seus clientes na obtenção do valor máximo de uso de seus produtos, uma vez que poderão compreender mais profundamente seus negócios e a relação com os produtos.

A vantagem competitiva perante os concorrentes é também uma provável consequência do serviço de pós-vendas, pois supõe-se que os produtos ofertados apresentam um desempenho além da média, podendo inclusive contribuir para que os clientes tenham ganhos financeiros através do melhor uso e manutenção dos mesmos. Assim, espera-se conquistar a fidelidade do cliente que tanto poderá voltar a comprar os produtos da empresa, quanto poderá comentar positivamente sobre sua experiência para as pessoas do seu ciclo.

\section{Conclusão}

O objetivo desse artigo foi o desenvolvimento de um serviço para uma empresa de autoclaves da região de Joinville/SC. Através da metodologia de design e ferramentas de Design de Serviços foi feita visita in loco na fábrica do cliente, onde ocorreu uma palestra para melhor conhecimento. Após isso, pesquisas foram realizadas no site da empresa e no de seus concorrentes para observar as oportunidades de serviços existentes para o ramo. Por fim, foi criado o serviço de pós-venda e manutenção, baseado no objetivo de satisfazer e fidelizar os clientes do estudo de caso, já que foi observado que o pós-venda existente na empresa era muito limitado.

O resultado que se espera com a conclusão do trabalho é que o mesmo sirva de base para ampliar a visão de gestores de empresas fabricantes de produtos, tendo como base o marketing estratégico de fidelização de clientes. A utilização da proposta pode ter implicações na lucratividade da empresa, aumento do número de clientes e fidelização e satisfação dos já existentes, se aplicada de forma eficiente, sendo realizada por profissionais altamente capacitados. 


\section{Referências}

AGUIAR, Victor Rafael Laurenciano. Atendimento ao cliente: novos cenários, velhos desafios. Blumenau: Nova Letra, 2014.

BAXTER, Mike. Projeto de produto: Guia prático para o design de novos produtos. São Paulo: $2^{\circ}$ ed, EdgadBlücher, 2000.

DRAFT. Design de Serviço. Disponível em: <http://projetodraft.com/verbete-draft-o-que-edesign-de-servico/>. Acesso em: 29 de maio de 2016.

KOTLER, Philip. Administração De Marketing. São Paulo: 12º ed., 2009

KOTLER, Philip; KELLER, Kevin Lane. Administração de Marketing. São Paulo: $5^{\circ}$ ed, Atlas, 1988.

LIVEWORK; Ferramenta: Blueprint de Serviço. Disponível em:<http://www.liveworkstudio.com.br/ferramenta-blueprint-de-servico/>.Acesso em $30 \mathrm{de}$ maio de 2016.

LIVEWORK. Inovação e Design de serviço. Disponível em:<http://www.liveworkstudio.com.br/o-que-fazemos/customer-experience/>. Acesso em: 29 de maio de 2016.

LOVELOCK, Christopher; WRIGHT, Lauren. Serviços: Marketing Gestão. São Paulo: Saraiva, 2001.

PAZMINO, Ana Veronica. Como se Cria: 40 Métodos para design de produtos. São Paulo: Blucher, 2015.

RODRIGUES, Kelly Poliana; SILVA, Leandro Cesar Diniz da; ANDRADE, Alexandre Pires de. Uma analise das ações de pós-venda como estratégia de fidelização. Disponível em: <http://convibra.org/upload/paper/adm/adm_3038.pdf>. Acesso em: 30 de maio de 2016.

TEIXEIRA, Fabricio. Introdução e boas práticas em UX design. São Paulo: casa do Código, 2014

TEIXEIRA, Fabrício. Métodos e estratégias de UX. Disponível em: <http://fabricio.nu/metodos/>. Acesso em: 29 de maio de 2016. 